\title{
Disseminated intravascular coagulation and subdural hemorrhage in a known case of prostate cancer: a case report
}

\author{
Alireza hadizadeh ${ }^{1}$, mahan shafie ${ }^{1}$, and samaneh parsa ${ }^{1}$ \\ ${ }^{1}$ Tehran University of Medical Sciences
}

August 13, 2022

\begin{abstract}
Disseminated intravascular coagulation is a major complication of both solid tumors and hematologic cancers which could result in bleeding in various sites. Our known case of prostate cancer experienced DIC and subdural hemorrhage. this rare incidence indicates that chronic DIC and SDH be suspected in such cases
\end{abstract}

Title

Disseminated intravascular coagulation and subdural hemorrhage in a known case of prostate cancer: a case report

Keywords

Disseminated intravascular coagulation - subdural hemorrhage - prostate cancer

Introduction

Among the well-documented activators of coagulative pathways are dysplastic cancers both solid tumors and hematologic cancers. [1] [2] This often presents as disseminated intravascular coagulation which is characterized as simultaneous consumption of coagulative factors, including both proteins and thrombocytes (which causes spontaneous hemorrhage), and intravascular coagulation which leads to deposition of clots in small vessels and subsequent organ failure. [1] [3] DIC usually occurs due to an underlying disease, therefore, in cases with no positive history, a prompt evaluation for diseases such as malignancies or chronic inflammatory diseases should be made. [4] [5] The signs and symptoms for DIC includes various forms from chest pain and dyspnea which is a sign of deposition of clots in lung to bleeding from various sites. [6] As these cases suffer from coagulation disorders, bleeding could potentially happen in all sites; [6] [7] however, subdural hemorrhage is a rare location for bleeding. [8] [9] In this study we present a case who was a 68year-old man who was previously diagnosed with metastatic prostate cancer and during the course showed signs of decompensated (preserved EF) heart failure and subdural hemorrhage. His condition became worse as DIC and subsequent SDH lead to irreversible brain damage and death.

Case presentation

(Figure 1)

(Figure 2)

(Figure 3)

Table 1. Pleural fluid analysis 


\begin{tabular}{llll}
\hline WBC & $44\left(/ \mathrm{mm}^{3}\right)$ & Glucose & $91(\mathrm{mg} / \mathrm{dL})$ \\
\hline Poly & $36\left(/ \mathrm{mm}^{3}\right)$ & LDH & $223($ unit $/ \mathrm{L})$ \\
Lymph & $64(\%)$ & WBC & $0-1(\mathrm{HPF})$ \\
RBC & $500(\%)$ & RBC & $1-2(\mathrm{HPF})$ \\
Albumin & $1800(\mathrm{mg} / \mathrm{dL})$ & Bacteria (Gram Stain) & Negative \\
Protein & $2700(\mathrm{mg} / \mathrm{dL})$ & Culture & Negative \\
\hline
\end{tabular}

WBC, white blood cell; RBC, red blood cell; LDH, lactate dehydrogenase

Table 2. Laboratory Data

\begin{tabular}{llll}
\hline WBC & $7.7\left(\times 1000 / \mathrm{mm}^{3}\right)$ & ALT & $35($ unit/L) \\
\hline $\mathrm{Hb}$ & $8.6(\mathrm{~g} / \mathrm{dL})$ & ALP & $1768(\mathrm{unit} / \mathrm{L})$ \\
$\mathrm{Plt}$ & $50\left(\times 1000 / \mathrm{mm}^{3}\right)$ & Bilirubin Total & $1.3($ unit/L) \\
$\mathrm{Na}$ & $139(\mathrm{meq} / \mathrm{L})$ & Bilirubin Direct & $0.6(\mathrm{unit} / \mathrm{L})$ \\
$\mathrm{K}$ & $4.6(\mathrm{meq} / \mathrm{L})$ & Cr & $1.7(\mathrm{mg} / \mathrm{dL})$ \\
$\mathrm{Ca}$ & $7.9(\mathrm{meq} / \mathrm{L})$ & Urea & $72(\mathrm{mg} / \mathrm{dL})$ \\
$\mathrm{P}$ & $3.2(\mathrm{meq} / \mathrm{L})$ & Uric Acid & $9.4(\mathrm{mg} / \mathrm{dL})$ \\
$\mathrm{Mg}$ & $2(\mathrm{meq} / \mathrm{L})$ & LDH & $748(\mathrm{unit} / \mathrm{L})$ \\
$\mathrm{pH}$ & 7.48 & Albumin & $3.5(\mathrm{~g} / \mathrm{dL})$ \\
$\mathrm{pCO} 2$ & $32(\mathrm{mmHg})$ & Total Protein & $5.8(\mathrm{~g} / \mathrm{dL})$ \\
$\mathrm{HCO} 3$ & $24(\mathrm{mmol} / \mathrm{L})$ & Retic Count & 7.9 \\
$\mathrm{PT}$ & $26(\mathrm{Sec})$ & Corrected Retic Count & 5.4 \\
$\mathrm{PTT}$ & $60(\mathrm{Sec})$ & CRP & $40(\mathrm{mg} / \mathrm{L})$ \\
$\mathrm{INR}$ & 2.2 & ESR & $5(\mathrm{~mm} / \mathrm{hour})$ \\
Fibrinogen & $47(\mathrm{mg} / \mathrm{dL})$ & Ferritin & $311(\mathrm{ng} / \mathrm{ml})$ \\
FDP & $160(\mu \mathrm{m} / \mathrm{mL})$ & HBS Ag & Non-reactive \\
D Dimer & $7333(\mathrm{ng} / \mathrm{mL})$ & Anti-HCV & Non-reactive \\
AST & $42(\mathrm{unit} / \mathrm{L})$ & HIV Ag/Ab & Non-reactive \\
\hline
\end{tabular}

WBC, white blood cell; RBC, red blood cell; Plt; platelets; PT, prothrombin time; PTT, partial thromboplastin time; INR, international normalized ratio; FDP, Fibrin degradation products, AST, aspartate aminotransferase; ALT, alanine aminotransferase; ALP, alkaline phosphatase; Cr, creatinine; LDH, lactate dehydrogenase; CRP, c-reactive protein; ESR, erythrocyte sedimentation rate

Discussion

This study reports a case who was previously diagnosed with metastatic prostate cancer and had refused further treatment 2 years prior to admittance. when he was presented to the emergency department, he showed signs of volume overload and had experienced minor falls. His evaluations revealed mild subdural hemorrhage and pleural effusion which turned out to be exudative. During the course of hospitalization, the patient developed DIC and subsequently subdural hemorrhage.

DIC occurs due to widespread activation of coagulation pathways, characterized by thrombotic occlusion of blood vessels which can compromise organ blood supply, and at the same time, increased probability of bleeding secondary to consumption of coagulation factors and platelets. DIC usually occurs secondary to an underlying cause including severe trauma, severe infectious disease, obstetric disorders, reactions to toxins, immunological disorders, and hematological and solid malignancies, so it is important to search for underlying conditions in cases with no apparent cause. [5] Association between DIC and malignancies has been well documented by potential mechanisms such as procoagulants secreted by malignant cells. [10] [1] 
As there is no single diagnostic test for DIC it is conventionally characterized by prolonged PT and APTT, low fibrinogen, raised fibrinogen degradation products and D-dimer, and low platelet count. Lower fibrinogen levels usually indicate a more severe DIC, however, as fibrinogen is an acute-phase reactant, serial measurements can be a more reliable indicator. [5]

International Society of Thrombosis and Hemostasis has set the criteria by which DIC could be identified. According to this criteria, a score greater than or equal to five is suggestive of DIC (Table 3). [7]

Table 3. International Society of Thrombosis and Hemostasis Scoring System for DIC.

\begin{tabular}{lll}
\hline Laboratory Test & Result & Score \\
\hline Platelet count & $>100 \times 109 / \mathrm{L}$ & 0 \\
& $<100 \times 109 / \mathrm{L}$ & 1 \\
& $<50 \times 109 / \mathrm{L}$ & 2 \\
Elevated fibrin-related marker (FDP/D-dimer) & No increase & 0 \\
& Moderate increase & 2 \\
& Strong increase & 3 \\
Prothrombin time & $<3 \mathrm{~s}$ & 0 \\
& $>3 \mathrm{but}<6 \mathrm{~s}$ & 1 \\
Fibrinogen level & $>6 \mathrm{~s}$ & 2 \\
& $>1.0 \mathrm{~g} / \mathrm{L}$ & 0 \\
& $<1.0 \mathrm{~g} / \mathrm{L}$ & 1 \\
\hline
\end{tabular}

DIC is the most common coagulation complication associated with prostate cancer with an incidence rate of $13 \%$ to $30 \%$. DIC in prostate cancer can become complicated with either spontaneous hemorrhage in various sites or thrombotic events. The presentations of bleeding vary from mild petechia and ecchymosis to severe gastrointestinal or intracranial bleeding while thrombotic events could cause venous or arterial thromboembolism in multiple organs and result in ischemia. Even though complications of DIC could be very serious, DIC is rarely symptomatic in prostate cancer and is present in only $0.4-1.65 \%$ of patients and most of the patients remain clinically asymptomatic. [11]

chronic DIC is a common presentation in patients with malignancies. It results from a persistent weak or intermittent coagulation activating stimulus. We assume that our patient suffered from this phenomenon as his impaired coagulation tests and SDH suggests.[12]

Spontaneous intracranial hemorrhage can occur in patients with malignancies due to various etiologies, but the most common cause is DIC. [13] A study conducted by Navi et al. assessed 208 known cancer subjects who also developed intracranial hemorrhage. This study acknowledges that coagulopathy and intra-tumoral hemorrhage constitutes a majority of the hemorrhages, while hypertension played a minor role. [2]

In this case, a brain CT scan revealed subdural hemorrhage which is suspected to be a consequence of chronic DIC but other etiologies could not be completely ruled out. the association between DIC and intracranial hemorrhage and various cancers has been well documented. [13] Kojima et al. has reported a case of a man who was presented with a sudden disturbance of consciousness and right hemiplegia. This patient was diagnosed with intracranial hemorrhage secondary to DIC. The following workup revealed occult prostate cancer. [14] Claes et al. reported a case who was previously diagnosed with prostate cancer two years prior to presentation to the emergency department with left facial palsy and confusion. He was also diagnosed with intracerebral hematoma due to DIC. [15]

The primary approach to the management of DIC is the treatment of the underlying cause. The management also involves appropriate supportive care for the impaired coagulative state. Life-threatening conditions such as excessive hemorrhage could indicate transfusion of fresh frozen plasma, cryoprecipitate, and platelets along with administration of antifibrinolytic agents such as tranexamic acid or epsilon aminocaproic acid. DIC 
patients with predominant thrombosis could benefit from therapeutic level heparin administration. Moreover, in patients with DIC secondary to prostate cancer, hormonal therapy, radiopharmaceutical therapy, and chemotherapy are presumed and stated to be effective. [11] [16] while our patient was under supportive care with cryoprecipitate and fresh frozen plasma, his subdural hemorrhage expanded. His cancer was left untreated for 2 years and had progressed and spread to bones. Hence, the care could not prevent the exacerbation of hemorrhage.

The International Prognostic Index (IPI) evaluates multiple factors such as age and stage of a disease and hence provides a score by which survival rate is assessed. Using this method, we calculated a score of 5 which shows low survival rate even if the patient survived DIC and SDH. [17-19]

This case verifies the fact that patients with prostate cancer could present with intracranial hemorrhage secondary to DIC. Therefore, in cases that are presented to clinics and EDs with DIC and ICH or SDH, a thorough and systemic workup for malignancies particularly prostate cancer could be effective.

\section{Declarations}

\section{Ethics approval and consent to participate}

This study was approved by the research and ethics committee of Tehran University of Medical Sciences. The patient's family have given their informed consent to publish this case.

\section{Consent for publication}

Written informed consent was obtained from the patient's next of kin for publication of this case report and any accompanying images. A copy of the written consent is available for review by the Editor-in-Chief of this journal.

\section{Availability of data and materials}

Data sharing is not applicable to this article as no datasets were generated or analyzed during the current study.

\section{Competing interests}

The authors have no conflict of interest to declare.

\section{Funding}

None

\section{Authors' contribution}

AH contributed in developing the research idea and composing and revising the manuscript. MS contributed in composing and revising the manuscript. SP contributed in developing the research idea and revising the manuscript.

\section{Acknowledgments}

None

\section{References}

1. Disseminated intravascular coagulation in cancer: an update. Seminars in thrombosis and hemostasis; 2019. Thieme Medical Publishers.

2. Navi B, Reichman J, Berlin D, et al. Intracerebral and subarachnoid hemorrhage in patients with cancer. Neurology 2010;74 (6):494-501

3. Sohal S, Thakur A, Zia A, Sous M, Trelles D. Disseminated Intravascular Coagulation and Malignancy:

A Case Report and Literature Review. Case reports in oncological medicine 2020;2020 
4. Feinstein DI. Disseminated intravascular coagulation in patients with solid tumors. Oncology 2015;29 (2):96-96

5. Costello RA, Nehring SM. Disseminated Intravascular Coagulation. StatPearls [Internet] 2021

6. Venugopal A. Disseminated intravascular coagulation. Indian journal of anaesthesia 2014;58 (5):603

7. Taylor Jr FB, Toh C-H, Hoots KW, Wada H, Levi M. Towards definition, clinical and laboratory criteria, and a scoring system for disseminated intravascular coagulation. Thrombosis and haemostasis 2001;86 (11):1327-30

8. Duran I, Tannock IF. Disseminated intravascular coagulation as the presenting sign of metastatic prostate cancer. Journal of general internal medicine 2006;21 (11):C6-C8

9. Velander AJ, DeAngelis LM, Navi BB. Intracranial hemorrhage in patients with cancer. Current atherosclerosis reports 2012;14 (4):373-81

10. Sallah S, Wan JY, Nguyen NP, Hanrahan L, Sigounas G. Disseminated intravascular coagulation in solid tumors: clinical and pathologic study. Thrombosis and haemostasis 2001;86 (09):828-33

11. Agrawal K, Agrawal N, Miles L. Disseminated intravascular coagulation as an initial manifestation of metastatic prostate cancer emergently treated with docetaxel-based chemotherapy. Case reports in oncological medicine 2019;2019

12. Somashekhar M, Kadamba PS, Wakodkar M. Chronic disseminated intravascular coagulation presenting as renal mass. Journal of Indian Association of Pediatric Surgeons 2008;13 (4):144

13. Rogers L. Cerebrovascular complications in patients with. Cancer Semin Neurol 30: 311-319, 2010.

14. Kojima A, Okui S. Intracranial hemorrhage as the initial presentation of disseminated intravascular coagulation in association with malignancy. Journal of Stroke and Cerebrovascular Diseases 2012;21 (8):912. e1-12. e3

15. Claes F, Verhagen CV, Verhagen WI, Schaafsma E, Rongen RJ. Acute isodense intracerebral haematoma due to coagulopathy associated with prostate cancer. Clinical neurology and neurosurgery 2007;109 (6):52022

16. Desai M, John B, Evans G, Eddy B. Prostate cancer: beware of disseminated intravascular coagulation. Case Reports 2015;2015 :bcr2014206814

17. Asadi A, Mahmoudi H, Mortezazadeh M. Peripheral T-cell Lymphoma of the oral cavity: a case report. Authorea Preprints 2021

18. Mofidi A, Esfandbod M, Pendar E, Mortezazadeh M, Hadizadeh A. Primary diffuse large B-cell lymphoma of the bone mimicking osteomyelitis. Clinical Case Reports 2021;9 (9):e04724

19. Schaffel R, Hedvat C, Teruya-Feldstein J, et al. Prognostic impact of proliferative index determined by quantitative image analysis and the International Prognostic Index in patients with mantle cell lymphoma. Annals of Oncology 2010;21 (1):133-39 


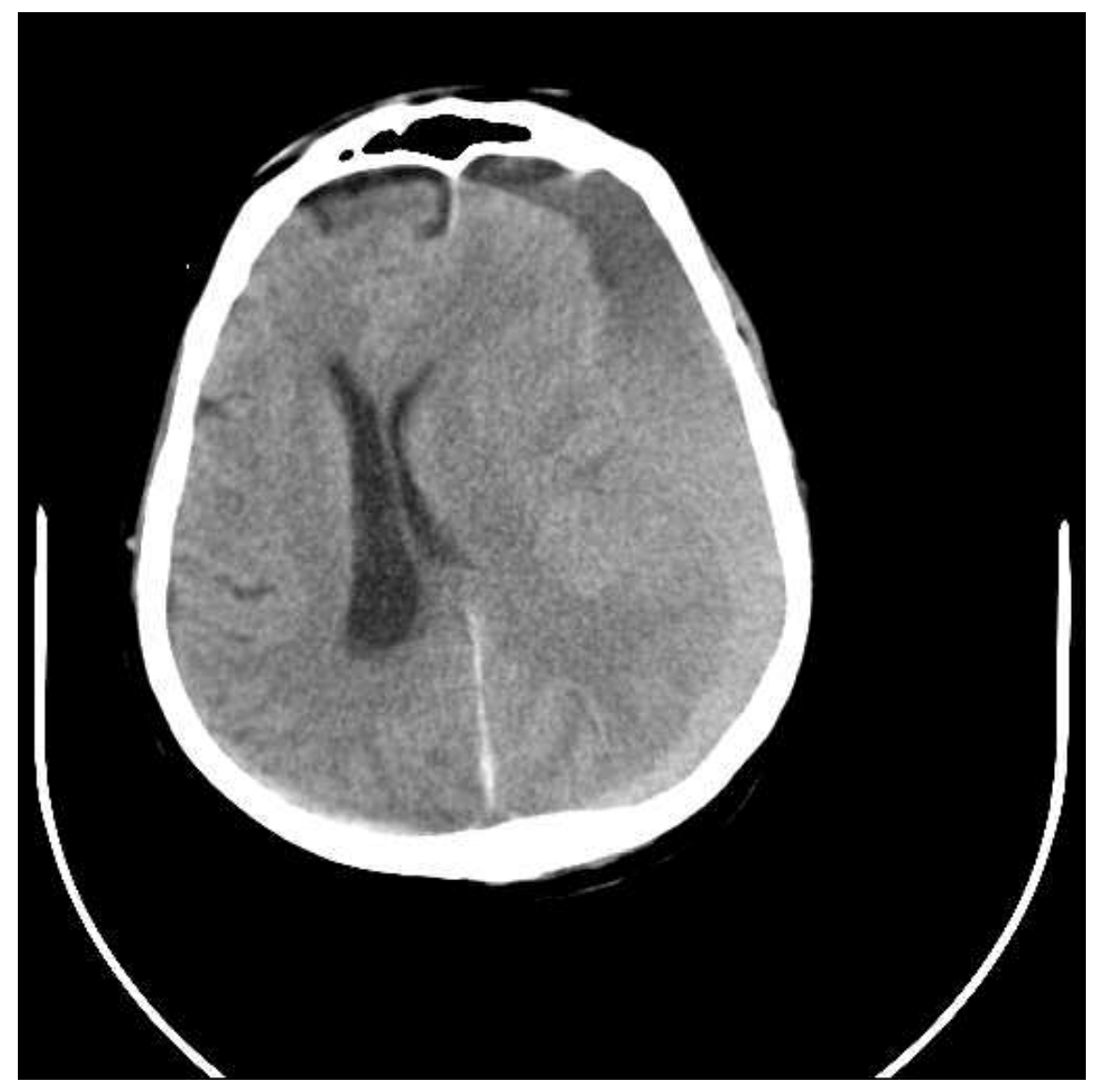

Figure 1. Axial cranial CT scan set at brain window; this cut depicts subdural hemorrhage and midline shift 


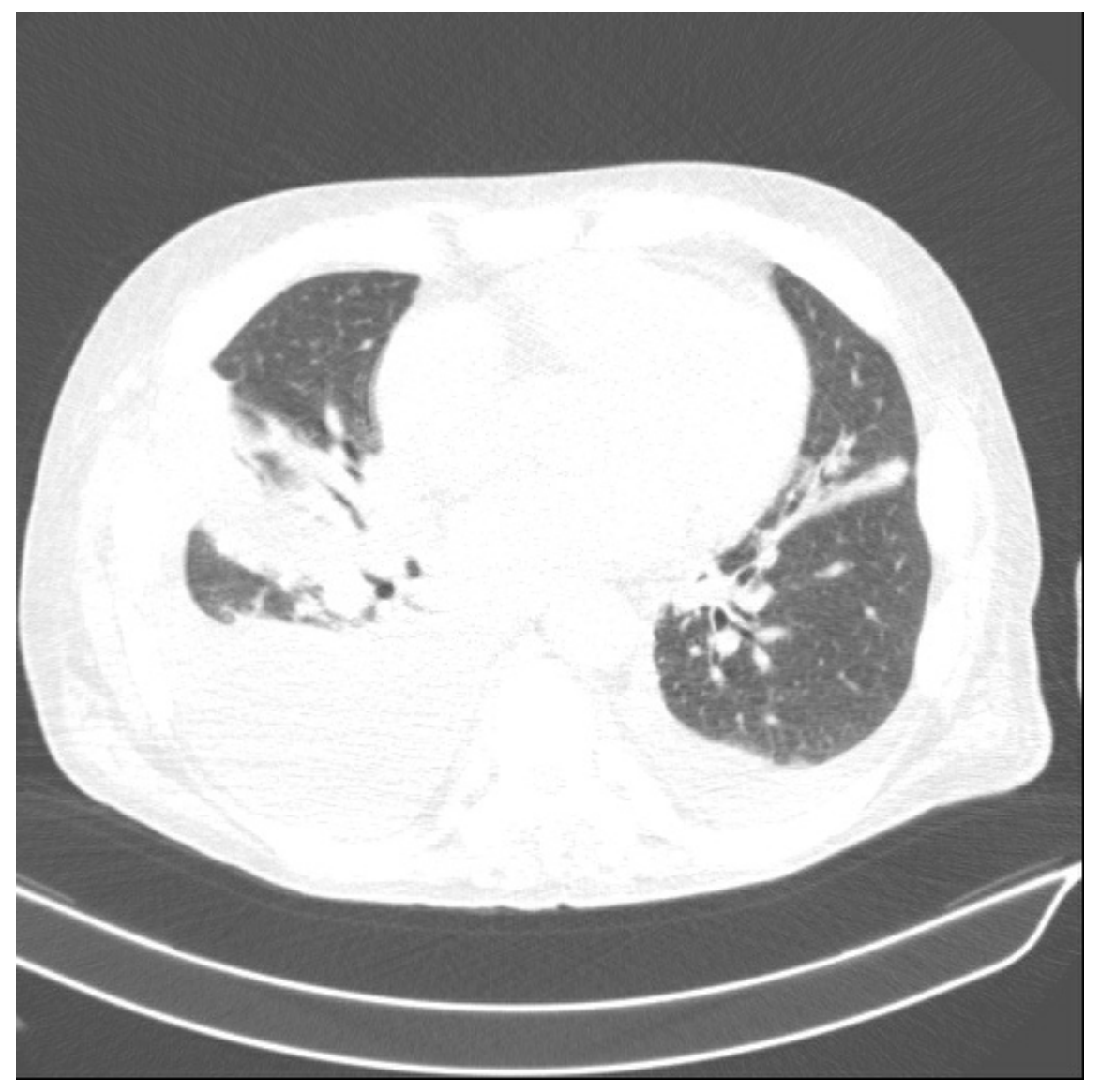

Figure 2. Axial thoracic CT scan cut of lower thoracic region set at pulmonary window; this cut depicts pleural effusion, ground glass opacity and collapse consolidation 


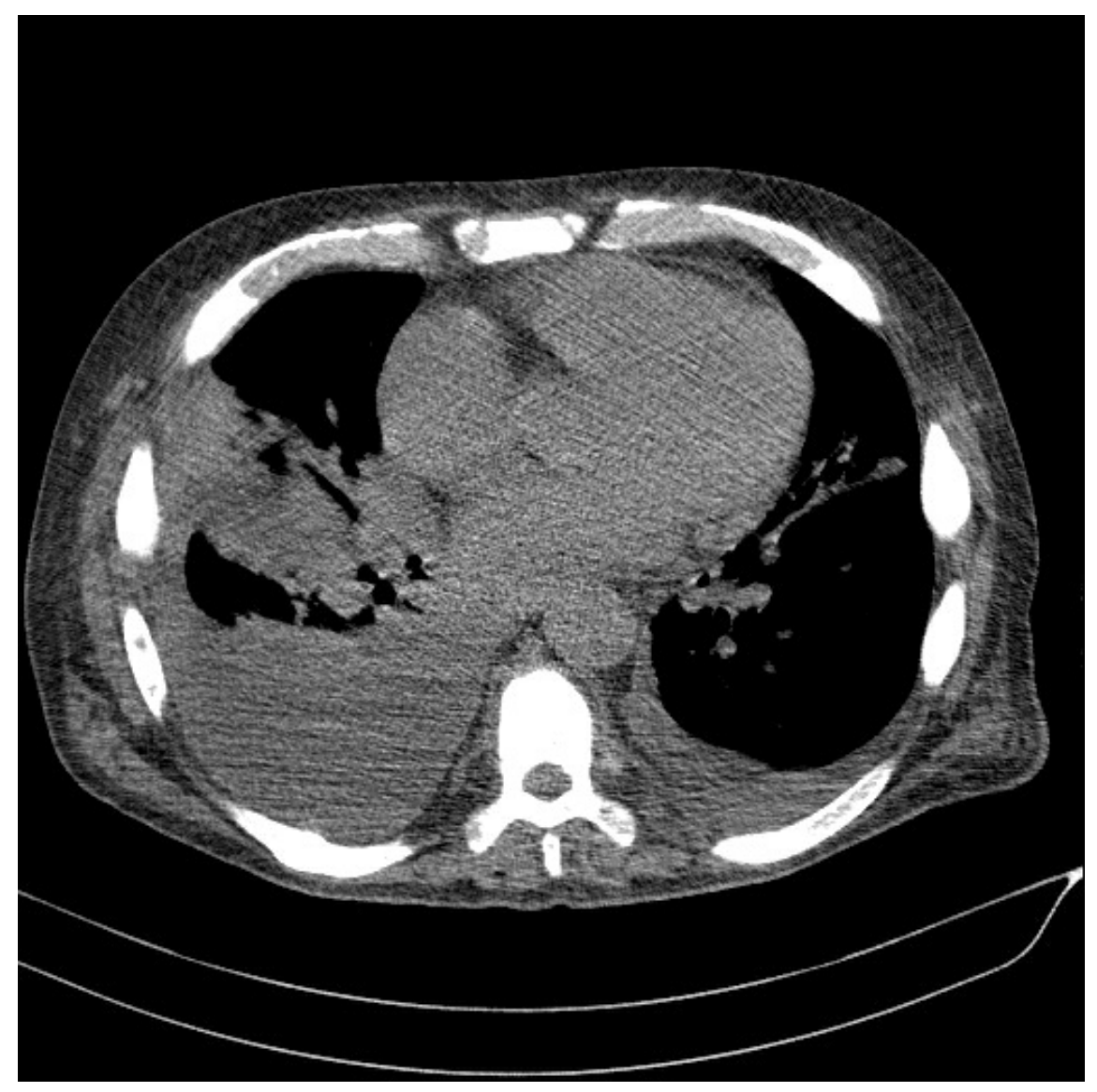

Figure 3. Axial thoracic CT scan cut of lower thoracic region set at thoracic window; in this cut pericardial effusion is also noticeable. 